Check for updates

Cite this: Chem. Commun., 2021, 57,6062

Received 2nd March 2021 Accepted 17th May 2021

DOI: 10.1039/d1cc01143j

rsc.li/chemcomm

\section{Nucleophilic transformations of azido-containing carbonyl compounds via protection of the azido group $\dagger$}

\author{
Takahiro Aimi, ${ }^{a}$ Tomohiro Meguro, ${ }^{a}$ Akihiro Kobayashi, ${ }^{\text {ab }}$ Takamitsu Hosoya (D) *a \\ and Suguru Yoshida (D) *ab
}

\begin{abstract}
Nucleophilic transformations of azido-containing carbonyl compounds are discussed. The phosphazide formation from azides and di(tert-butyl)(4-(dimethylamino)phenyl)phosphine (Amphos) enabled transformations of carbonyl groups with nucleophiles such as lithium aluminum hydride and organometallic reagents. The good stability of the phosphazide moiety allowed us to perform consecutive transformations of a diazide through triazole formation and the Grignard reaction.
\end{abstract}

Azides are of great significance in a broad range of research fields including synthetic organic chemistry, chemical biology, and materials chemistry. ${ }^{1}$ Diverse reliable transformations of azides such as copper-catalyzed azide-alkyne cycloaddition (CuAAC), ${ }^{2}$ strain-promoted azide-alkyne cycloaddition (SPAAC), ${ }^{3}$ the Staudinger reaction, ${ }^{4}$ and reduction into amines ${ }^{5}$ have been used in the synthesis of various organonitrogen compounds (Fig. 1A). One drawback of azide chemistry is that an azido group is easily damaged with various nucleophiles due to the high electrophilicity. ${ }^{1,6,7}$ We herein disclose selective nucleophilic transformations of a carbonyl group through the protection of the azido group (Fig. 1B and C).

In the course of our studies on azide ${ }^{4 d, e, 8,9}$ and organophosphorus chemistry, ${ }^{9,10}$ we recently found a protection method for the azido group from CuAAC and SPAAC reactions by phosphazide formation with di(tert-butyl)(4-(dimethylamino)phenyl)phosphine (Amphos) (Fig. 1B). ${ }^{9}$ The phosphazide formation took place smoothly without forming azaylides through

\footnotetext{
${ }^{a}$ Laboratory of Chemical Bioscience, Institute of Biomaterials and Bioengineering,

Tokyo Medical and Dental University (TMDU), 2-3-10 Kanda-Surugadai,

Chiyoda-ku, Tokyo 101-0062, Japan.E-mail: s-yoshida@rs.tus.ac.jp,

thosoya.cb@tmd.ac.jp

${ }^{b}$ Department of Biological Science and Technology,

Faculty of Advanced Engineering, Tokyo University of Science,

6-3-1 Niijuku, Katsushika-ku, Tokyo 125-8585, Japan

$\dagger$ Electronic supplementary information (ESI) available: Experimental procedures, and characterization of new compounds including NMR spectra. See DOI: $10.1039 / \mathrm{d} 1 \mathrm{cc} 01143 \mathrm{j}$
}

a denitrogenation process. The deprotection was easily realized by treating with elemental sulfur to afford azides in high yields. Considering the significance of azides in synthetic organic chemistry, we focused on the stability of phosphazides under nucleophilic or radical conditions for transformations of azides, which were still unclear due to the possible equilibrium liberation of azides from phosphazides under various conditions. ${ }^{9}$

We firstly examined denitrogenative reductions of azide 1a and phosphazide 4 (Fig. 2). As a result, aniline 2 was obtained

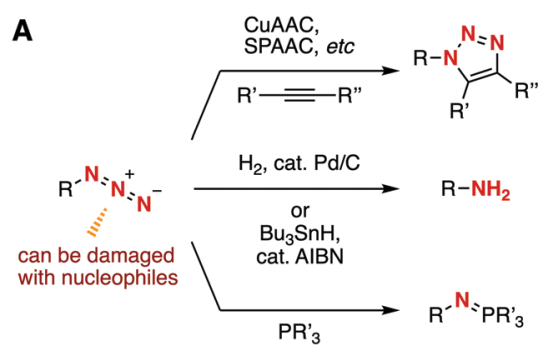

B Previous work
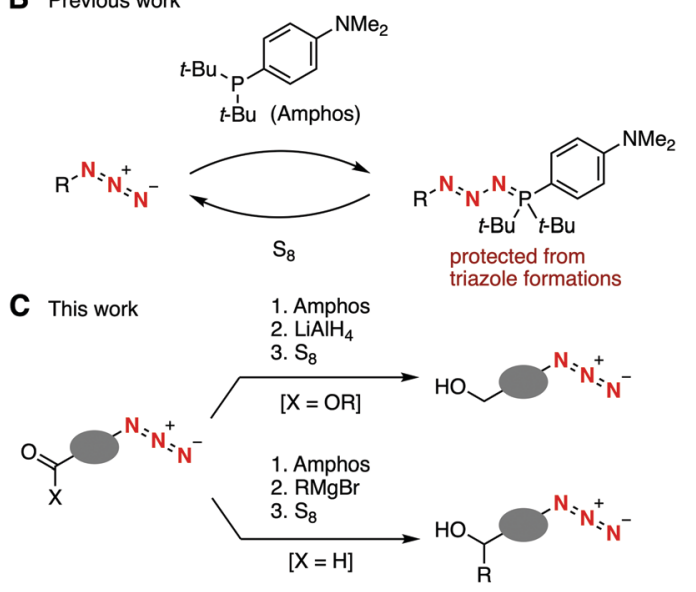

Fig. 1 Backgrounds and plan of this study. (A) Conventional transformations of azides. (B) Our previous work. (C) This work. 


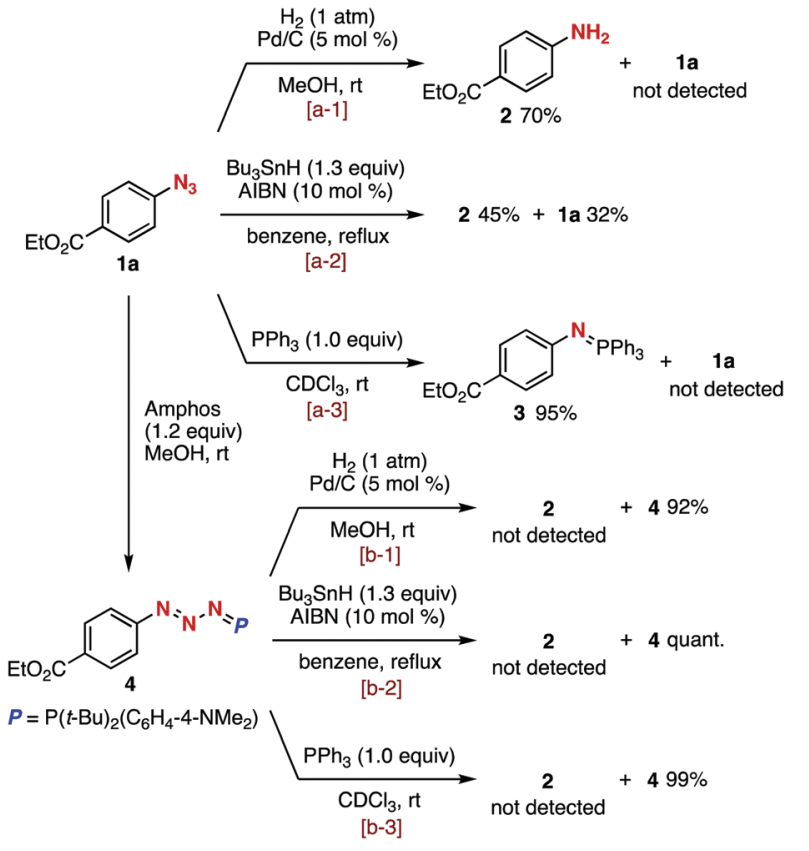

Fig. 2 Transformations of azide $\mathbf{1 a}$ and phosphazide $\mathbf{4}$ under reductive conditions.

by hydrogenation of azide 1a catalyzed by $\mathrm{Pd} / \mathrm{C}$ under a hydrogen atmosphere (Fig. 2, a-1) or radical-mediated reduction with tributylstannane and 2,2'-azodiisobutyronitrile (AIBN) (Fig. 2, a-2). The Staudinger reaction of azide 1a with triphenylphosphine furnished azaylide 3 in high yield (Fig. 2, a-3). In contrast, we found that phosphazide 4 prepared from azide 1a with Amphos was stable under the reductive conditions using $\mathrm{Pd} / \mathrm{C}$ and $\mathrm{H}_{2}$ (Fig. 2, b-1), tributylstannane and AIBN (Fig. 2, b-2), or triphenylphosphine (Fig. 2, b-3). These results obviously indicated that azides can be protected by phosphazide formation under various reduction conditions, although azides can form in equilibrium from phosphazides. $^{9}$

Ester-selective lithium aluminum hydride (LAH) reduction was achieved through the phosphazide formation (Fig. 3). ${ }^{6}$ While the treatment of azide 1a with LAH in tetrahydrofuran (THF) at $-20{ }^{\circ} \mathrm{C}$ provided 4-aminobenzyl alcohol (5) and 4-(ethoxycarbonyl)aniline (2) via reduction of the azido group (Fig. 3A, upper), pretreatment of azide 1a with Amphos at room temperature followed by the addition of $\mathrm{LAH}$ at $-20{ }^{\circ} \mathrm{C}$ and subsequent deprotection using elemental sulfur successfully afforded 4-azidobenzyl alcohol (6a) by selective reduction of the ethoxycarbonyl group leaving the azido group untouched (Fig. 3A, lower). ${ }^{11}$ It is worth noting that the phosphazide moiety tolerated highly nucleophilic LAH. We also succeeded in the ester-selective LAH reduction of a broad range of azidosubstituted esters 1 via the formation of phosphazides (Fig. 3B). Indeed, phosphazide formation, LAH reduction, and deprotection with elemental sulfur took place efficiently using esters 1 to afford the corresponding alcohols $\mathbf{6 b}-\mathbf{6 f}$ in moderate to good yields via the protection of the heteroaromatic and primary, secondary, and tertiary alkyl azido groups. These results clearly show that a wide range of azido groups were protected using

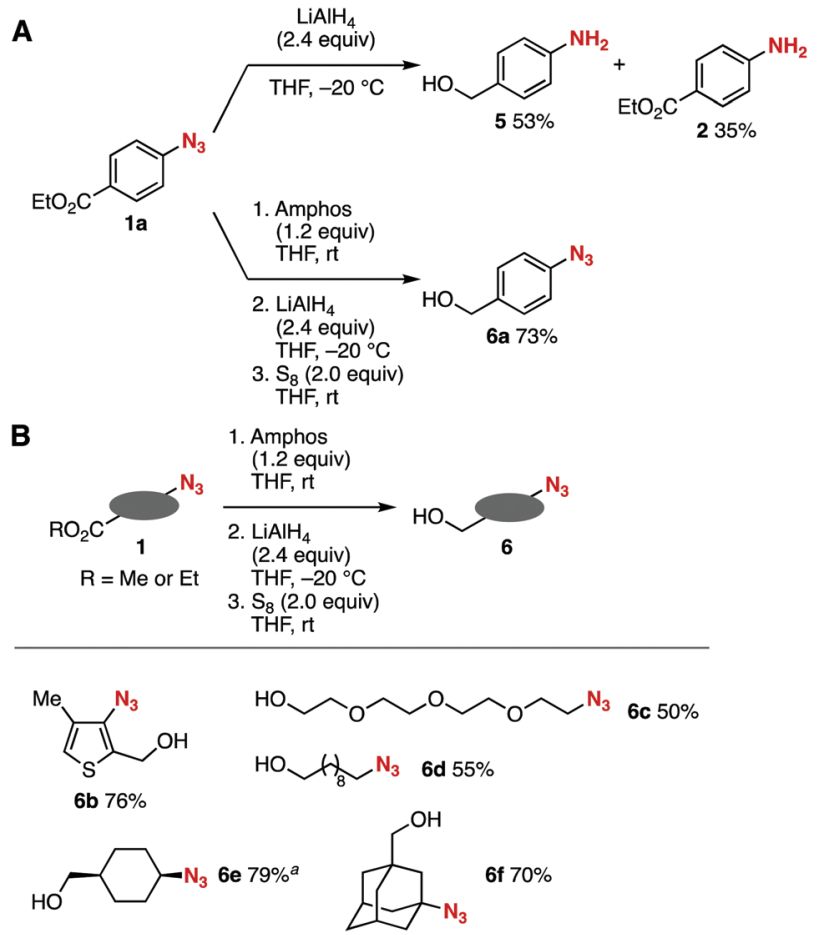

Fig. 3 Reduction of azido-substituted esters 1 with $\mathrm{LiAlH}_{4}$. (A) Reductions with or without the protection of azide 1a. (B) Scope of synthesized azidosubstituted alcohols $\mathbf{6}$. See ESI $\dagger$ for the structures of 1

Amphos even in the presence of highly nucleophilic reagents such as LAH.

The good stability of phosphazides toward nucleophiles allowed for alcohol synthesis from 4-azidobenzaldehyde (7a) with organomagnesium or organolithium reagents (Fig. 4). 7,12 The reaction between aldehyde $7 \mathbf{a}$ and ethylmagnesium bromide furnished aniline $\mathbf{9}$ in moderate yield along with a trace amount of alcohol 8a due to the denitrogenation reduction of the azido group (Fig. 4A, upper). In sharp contrast, we accomplished an efficient synthesis of alcohol 8a from aldehyde 7a and ethylmagnesium bromide without damaging the highly electrophilic aromatic azido group (Fig. 4A, lower). Indeed, the phosphazide formation of azide 7a with Amphos proceeded smoothly leaving the formyl group. Then, the addition of ethylmagnesium bromide to the resulting mixture followed by the deprotection with elemental sulfur furnished alcohol 8a in high yield keeping the azido group unreacted. The reaction performed at a $1 \mathrm{mmol}$ scale also proceeded efficiently to afford alcohol 8a in good yield. Thus, this simple single-purification procedure enabled the efficient Grignard reaction of the formyl group without damaging the azido group.

A wide variety of carbanions successfully participated in the azidosubstituted alcohol synthesis from aldehydes 7 (Fig. 4B and C). For example, phenylation, 4-chloro- and 4-methoxyphenylation, and 2-thienylation of aldehyde $7 \mathbf{a}$ efficiently proceeded to provide alcohols $\mathbf{8 b}-\mathbf{8 e}$ possessing an azido group in good yields. Benzylation and allylation of aldehyde $7 \mathbf{a}$ also took place smoothly to afford azido-substituted alcohols $\mathbf{8 f}$ and $\mathbf{8 g}$ in moderate to high yields. Bulky alkyl Grignard reagents such as isopropylmagnesium 
A

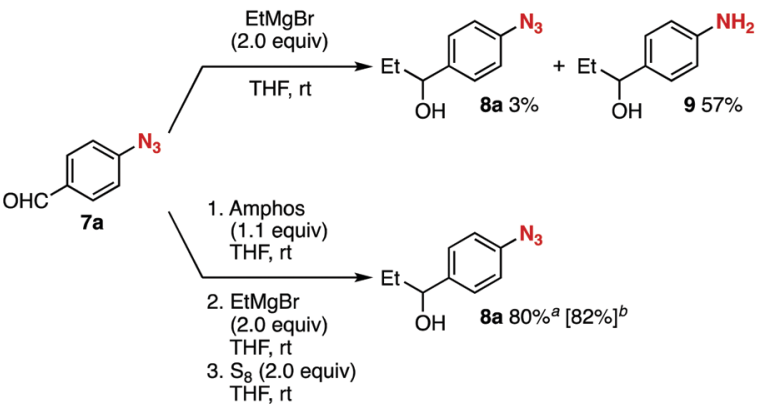

B

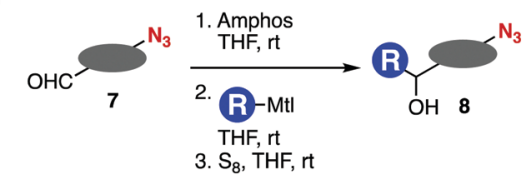

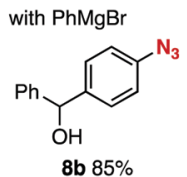

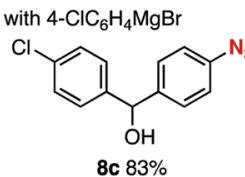

with 2-thienylMgBr<smiles>Nc1ccc(C(O)c2cccs2)cc1</smiles>

with $i-\mathrm{PrMgBr}$<smiles></smiles>

8h $61 \%$

with $n$-BuLi<smiles>CCCCC(O)c1ccc([N+](=O)[O-])cc1</smiles>

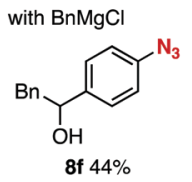

with $t$-BuMgCl<smiles>CC(C)(C)C(O)c1ccc([N+](=O)[O-])cc1</smiles>

8i $66 \%$

with PhLi

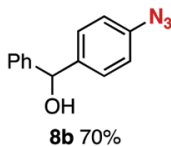

D with $\mathrm{EtMgBr}$<smiles>CCC(O)c1ccc(-c2ccc([N+](=O)[O-])cc2)cc1</smiles><smiles>CCC(O)c1cc([N+](=O)[O-])cc([N+](=O)[O-])c1</smiles>

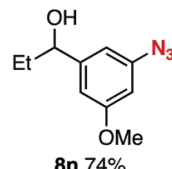<smiles>CCCCC(C)(F)c1cc(C(O)CC)cc([N+](=O)[O-])c1</smiles><smiles>CCC(O)c1cc(Br)cc([N+](=O)[O-])c1</smiles><smiles>CCC(O)c1ccccc1N</smiles><smiles>CCC(O)CCc1ccc([N+](=O)[O-])cc1</smiles>

Fig. 4 Azido-substituted alcohol synthesis with organomagnesium or organolithium reagents. (A) Grignard reaction with or without the protection of azide 7a. (B) General scheme. (C) Scope of synthesized azido-substituted alcohols 8 from 7a. (D) Scope of synthesized azido-substituted alcohols $\mathbf{8}$ from various azido-substituted aldehydes 7 . See ESI $\dagger$ for the structures of 7 . ${ }^{a}$ The isolated yield for the reaction conducted on a $0.2 \mathrm{mmol}$ scale. ${ }^{b}$ The isolated yield for the reaction conducted on a $1 \mathrm{mmol}$ scale.

bromide and tert-butylmagnesium chloride reacted with aldehyde 7a avoiding the reaction at the azido group. Of note, we achieved the introduction of a terminal alkyne moiety by the reaction using ethynylmagnesium bromide, furnishing azido-substituted propargyl alcohol 8j in good yield, which will serve in click chemistry. Also, organolithium reagents including $n$-butyllithium and phenyllithium were applicable to the addition reaction without damaging the phosphazide moiety.

The Grignard reactions of various aldehydes 7 bearing an azido group were accomplished to provide alcohols 81-8r in moderate to good yields (Fig. 4B and D). A broad range of aldehydes 7 efficiently reacted with ethylmagnesium bromide at the formyl group without damaging the azido group via phosphazide formation to yield alcohols 81-8p leaving methoxy, trifluoromethyl, and bromo groups intact. The azide protection followed by the Grignard reaction and deprotection uneventfully took place when using $o$-azidobenzaldehyde to provide $\mathbf{8 q}$ in good yield. Synthesis of secondary alcohol $8 \mathbf{r}$ was also achieved from an aliphatic aldehyde (3-(4-azidophenyl)propanal) and ethylmagnesium bromide via the azide protection with Amphos. These results clearly show that nucleophilic additions of formyl-substituted azides with a broad range of organomagnesium and organolithium reagents through the robust phosphazides realized the preparation of diverse alcohols having an azido group.

A synthetic utility of the Grignard reaction of aldehydes having azido groups was showcased by the consecutive reactions between diazide 10, cycloalkyne 12, and 4-methoxyphenylmagnesium bromide (Fig. 5). Firstly, the treatment of diazide 10 with an equimolar amount of Amphos resulted in the selective protection of the aromatic azido group by virtue of the stabilization by the benzene ring without phosphazide formation at the benzyl azide moiety. Secondly, the SPAAC reaction of phosphazide $\mathbf{1 1}$ with cycloalkyne $\mathbf{1 2}$ at the remaining benzylic azido group proceeded smoothly to afford cycloadduct 13. Thirdly, the Grignard reaction of aldehyde 13 with 4-methoxyphenylmagnesium bromide followed by the deprotection with elemental sulfur provided azide $\mathbf{1 4}$ in high yield. Since azides are of great importance in not only synthetic chemistry but also chemical biology, this four-step twopot method will allow us to construct a vast chemical library of a wide variety of triazoles having an aromatic azide moiety from formyl-substituted diazide 10, alkynes, and organometallic reagents through the phosphazide formation.

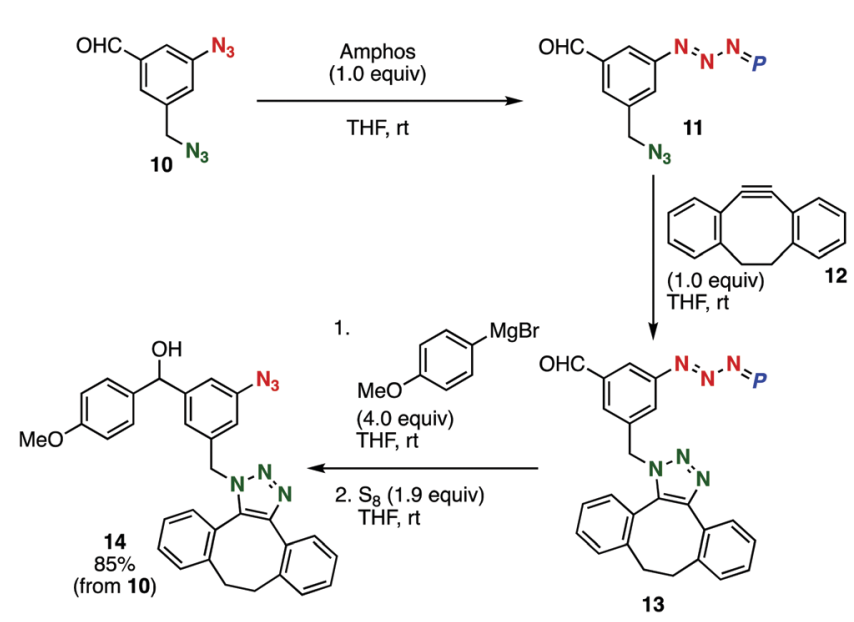

Fig. 5 Synthesis of azide 14 from diazide $\mathbf{1 0}$ 
In summary, we have accomplished nucleophilic transformations of diverse azides through phosphazide formation. Good stability of the phosphazide intermediates realized reduction of esters by LAH and addition reaction of aldehydes with organometallic reagents to provide a wide variety of azidosubstituted alcohols. Further studies to examine detailed properties of phosphazides, especially equilibrium liberation of azides, and to expand the applicability of the azide protection method are underway in our group.

The authors thank Dr Takashi Niwa (RIKEN, Center for Biosystems Dynamics Research (BDR)) and Dr Yuki Sakata (Tokyo Medical and Dental University) for HRMS analyses and Assoc. Prof. Dr Hiroki Tanimoto for helpful discussions. This work was supported by JSPS KAKENHI Grant Numbers JP19K05451 (C; S. Y.) and JP18H02104 (B; T. H.); the Naito Foundation (S. Y.); the Japan Agency for Medical Research and Development (AMED) under Grant Number JP20am0101098 (Platform Project for Supporting Drug Discovery and Life Science Research, BINDS); and the Cooperative Research Project of Research Center for Biomedical Engineering.

\section{Conflicts of interest}

There are no conflicts to declare.

\section{Notes and references}

1 (a) S. Bräse, C. Gil, K. Knepper and V. Zimmermann, Angew. Chem., Int. Ed., 2005, 44, 5188; (b) S. Bräse and K. Banert, Organic Azides: Syntheses and Applications, John Wiley \& Sons, Ltd, Chichester, 2010; (c) H. Tanimoto and K. Kakiuchi, Nat. Prod. Commun., 2013, 8, 1021; (d) K. Banert, Synthesis, 2016, 48, 2361; (e) D. Huang and G. Yan, Adv. Synth. Catal., 2017, 359, 1600; $(f)$ S. Yoshida, Org. Biomol. Chem., 2020, 18, 1550; $(g)$ Z.-K. Liu, Q.-Q. Zhao, Y. Gao, Y.-X. Hou and X.-Q. Hu, Adv. Synth. Catal., 2020, 363, 411.

2 (a) C. W. Tornøe, C. Christensen and M. Meldal, J. Org. Chem., 2002, 67, 3057; (b) V. V. Rostovtsev, L. G. Green, V. V. Fokin and K. B. Sharpless, Angew. Chem., Int. Ed., 2002, 41, 2596; (c) M. Meldal and C. W. Tornøe, Chem. Rev., 2008, 108, 2952; (d) A. Mandoli, Molecules, 2016, 21, 1174.

3 (a) N. J. Agard, J. A. Prescher and C. R. Bertozzi, J. Am. Chem. Soc., 2004, 126, 15046; (b) J. A. Codelli, J. M. Baskin, N. J. Agard and C. R. Bertozzi, J. Am. Chem. Soc., 2008, 130, 11486; (c) X. Ning, J. Guo, M. A. Wolfert and G.-J. Boons, Angew. Chem., Int. Ed., 2008, 47, 2253; (d) A. A. Poloukhtine, N. E. Mbua, M. A. Wolfert, G.-J. Boons and V. V. Popik, J. Am. Chem. Soc., 2009, 131, 15769; (e) J. Dommerholt, S. Schmidt, R. Temming, L. J. A. Hendriks, F. P. J. T. Rutjes, J. C. M. van Hest, D. J. Lefeber, P. Friedl and F. L. van Delft, Angew. Chem., Int. Ed., 2010, 49, 9422; $(f)$ J. C. Jewett, E. M. Sletten and C. R. Bertozzi, J. Am. Chem. Soc., 2010, 132, 3688; $(g)$ S. Yoshida, Y. Hatakeyama, K. Johmoto, H. Uekusa and T. Hosoya, J. Am. Chem. Soc., 2014, 136, 13590; $(h)$ R. Ni, N. Mitsuda, T. Kashiwagi, K. Igawa and K. Tomooka, Angew. Chem., Int. Ed., 2014, 54, 1190; (i) R. R. Ramsubhag and G. B. Dudley, Org. Biomol. Chem., 2016, 14, 5028; $(j)$ K. Kaneda, R. Naruse and S. Yamamoto, Org. Lett., 2017, 19, 1096; (k) E. G. Burke, B. Gold, T. T. Hoang, R. T. Raines and J. M. Schomaker, J. Am. Chem. Soc., 2017, 139, 8029; ( $l$ ) C. Lis, S. Rubner, C. Gröst, R. Hoffmann, D. Knappe and T. Berg, Chem. - Eur. J, 2018, 24, 13762; (m) S. Yoshida, T. Kuribara, H. Ito, T. Meguro, Y. Nishiyama,
F. Karaki, Y. Hatakeyama, Y. Koike, I. Kii and T. Hosoya, Chem. Commun., 2019, 55, 3556; (n) K. Adachi, T. Meguro, Y. Sakata, K. Igawa, K. Tomooka, T. Hosoya and S. Yoshida, Chem. Commun., 2020, 56, 9823; (o) N. Makio, T. Kuribara, K. Adachi, Y. Hatakeyama, T. Meguro, Y. Sakata, K. Igawa, K. Tomooka, T. Hosoya and S. Yoshida, Chem. Commun., 2020, 56, 11449.

4 (a) H. Staudinger and J. Meyer, Helv. Chim. Acta, 1919, 2, 635; (b) E. Saxon and C. R. Bertozzi, Science, 2000, 287, 2007; (c) S. S. van Berkel, M. B. van Eldijk and J. C. M. van Hest, Angew. Chem., Int. Ed., 2011, 50, 8806; (d) T. Meguro, S. Yoshida and T. Hosoya, Chem. Lett., 2017, 46, 473; (e) T. Meguro, N. Terashima, H. Ito, Y. Koike, I. Kii, S. Yoshida and T. Hosoya, Chem. Commun., 2018, 54, 7904; $(f)$ C. Bednarek, I. Wehl, N. Jung, U. Schepers and S. Bräse, Chem. Rev., 2020, 120, 4301.

5 (a) F. Rolla, J. Org. Chem., 1982, 47, 4327; (b) S. N. Maiti, P. Spevak and A. V. N. Reddy, Synth. Commun., 1988, 18, 1201; (c) G. V. Reddy, G. V. Rao and D. S. Iyengar, Tetrahedron Lett., 1999, 40, 3937; (d) A. M. Salunkhe, P. V. Ramachandran and H. C. Brown, Tetrahedron, 2002, 58, 10059; (e) A. Kamal, N. Shankaraiah, N. Markandeya and C. S. Reddy, Synlett, 2008, 1297; $(f)$ A. Kamal, N. Markandeya, N. Shankaraiah, C. R. Reddy, S. Prabhakar, C. S. Reddy, M. N. Eberlin and L. S. Santos, Chem. - Eur. J., 2009, 15, 7215; $(g)$ T. Maegawa, T. Takahashi, M. Yoshimura, H. Suzuka, Y. Monguchi and H. Sajiki, Adv. Synth. Catal., 2009, 351, 2091.

6 J. H. Boyer, J. Am. Chem. Soc., 1951, 73, 5865.

7 For reactions of azides with organometallic reagents, see: (a) P. A. S. Smith, C. D. Rowe and L. B. Bruner, J. Org. Chem., 1969, 34, 3430; (b) D. H. Sieh, D. J. Wilbur and C. J. Michejda, J. Am. Chem. Soc., 1980, 102, 3883; (c) B. M. Trost and W. H. Pearson, J. Am. Chem. Soc., 1981, 103, 2483; (d) B. M. Trost and W. H. Pearson, J. Am. Chem. Soc., 1983, 105, 1054; (e) K. Nishiyama and N. Tanaka, J. Chem. Soc., Chem. Commun., 1983, 1322; $(f)$ R. H. Smith, Jr. and C. J. Michejda, Synthesis, 1983, 476; (g) G. W. Kabalka and G. Li, Tetrahedron Lett., 1997, 38, 5777; (h) A. Nakhai, B. Stensland, P. H. Svensson and J. Bergman, Eur. J. Org. Chem., 2010, 6588; (i) A. A. Suleymanov, R. Scopelliti, F. F. Tirani and K. Severin, Org. Lett., 2018, 20, 3323; ( $j$ ) S. Graßl, J. Singer and P. Knochel, Angew. Chem., Int. Ed., 2020, 59, 335.

8 For our recent azide chemistry, see: (a) S. Yoshida, S. Goto, Y. Nishiyama, Y. Hazama, M. Kondo, T. Matsushita and T. Hosoya, Chem. Lett., 2019, 48, 1038; (b) H. Takemura, S. Goto, T. Hosoya and S. Yoshida, Chem. Commun., 2020, 56, 15541; (c) T. Meguro, Y. Sakata, T. Morita, T. Hosoya and S. Yoshida, Chem. Commun., 2020, 56, 4720; (d) N. Terashima, Y. Sakata, T. Meguro, T. Hosoya and S. Yoshida, Chem. Commun., 2020, 56, 14003; (e) S. Yoshida, Y. Sakata, Y. Misawa, T. Morita, T. Kuribara, H. Ito, Y. Koike, I. Kii and T. Hosoya, Chem. Commun., 2021, 57, 899.

9 T. Meguro, S. Yoshida, K. Igawa, K. Tomooka and T. Hosoya, Org. Lett., 2018, 20, 4126.

10 For our organophosphorus chemistry, see: $(a)$ S. Yoshida, K. Igawa and K. Tomooka, J. Am. Chem. Soc., 2012, 134, 19358; (b) S. Yoshida and T. Hosoya, Chem. Lett., 2013, 42, 583; (c) Y. Nishiyama, Y. Hazama, S. Yoshida and T. Hosoya, Org. Lett., 2017, 19, 3899; (d) Y. Nishiyama, S. Kamada, S. Yoshida and T. Hosoya, Chem. Lett., 2018, 47, 1216; (e) Y. Nishiyama, T. Hosoya and S. Yoshida, Chem. Commun., 2020, 56, 5771.

11 Alcohol 6a was not obtained when triphenylphosphine was used instead of Amphos. Treatment of azide 1a with tri(t-butyl) phosphinonium tetrafluoroborate and triethylamine followed by $\mathrm{LiAlH}_{4}$ reduction and subsequent deprotection with elemental sulfur furnished alcohol $6 \mathrm{a}$ in $61 \%$ yield.

12 For transformations of carbonyl group without damaging azido group, see: (a) S. Hanessian, R. R. Vakiti, S. Dorich, S. Banerjee, F. Lecomte, J. R. DelValle, J. Zhang and B. Deschênes-Simard, Angew. Chem., Int. Ed., 2011, 50, 3497; (b) S. Hanessian, R. R. Vakiti, S. Dorich, S. Banerjee and B. Deschênes-Simard, J. Org. Chem., 2012, 77, 9458; (c) K. Morihiro, N. Ankenbruck, B. Lukasak and A. Deiters, J. Am. Chem. Soc., 2017, 139, 13909. 